\title{
PERKEMBANGAN ISLAM DI SABAH MALAYSIA (Perspektif Sosio-Historis)
}

\author{
Syamruddin Nasution dan Abd. Ghofur \\ Universitas Islam Negeri Sultan Syarif Kasim Riau, Indonesia \\ syamruddin.nst@uin-suska.ac.id
}

\begin{abstract}
Abstrak
Sabah adalah salah satu Negara bagian Malaysia terbesar kedua setelah Sarawak. Islam masuk ke Sabah secara intensif terjadi pada abad ke $16 \mathrm{M}$ berasal dari kesultanan Brunei, dimulai dari kawasan pantai Barat Sabah. Sehingga kawasan tersebut menjadi bagian dari daerah kekuasaan Sultan Brunei yaitu pada masa Sultan Bolkiah (berkuasa 1485-1524 M) karena ia termasuk pemimpin yang suka berpetualangan ke berbagai wilayah disamping mendakwahkan Islam juga memperluas daerah kekuasaan. Persebaran penduduk melayu dan keuturunan raja-raja Brunei secara bertahap bermigrasi ke pantai Barat Sabah. Persebaran Islam di Sabah juga berasal dari pengaruh Kesultanan Sulu kepada penduduk lokal Sabah sekitar abad ke-17 M terutama di kawasan pantai Timur Sabah. Migrasi sebagian muslim dari kesultanan Sulu sebagai akibat dari tekanan dan serangan koloni Spanyol (1521-1898 M) di Philipina Utara (Luzon, Visayas) hingga ke Selatan (Mindanao, Sulu, Basilan, Tawi-tawi CotaBato). Mereka melakukan migrasi ke pantai Timur Sabah tidak lain karena letak georgrafis yang tidak terlalu jauh, namun juga untuk mendapatkan kehidupan yang lebh aman. Tulisan ini akan menguraikan lebih detil tentang persebaran Islam di Sabah sejak masa Kesultanan, masa kolonial dan perkemangan terkini dengan tinjuan sosio-historis.
\end{abstract}

Kata Kunci: Sabah, Islam, dan Malaysia.

\section{Pendahuluan}

Kajian sejarah masuk dan berkembangnya Islam di Sabah Malaysia, salah satu kajian yang menarik, karena Muslim Sabah dipengaruhi oleh dua kesultanan Brunei dan Sulu. Sabah merupakan salah satu negara bagian dari 13 negara bagian di Malaysia. Sabah adalah negara bagian kedua terbesar di Malaysia setelah Sarawak. Ibu kota negara bagian Sabah adalah Kota Kinabalu, dan saat masa zaman jajahan Inggris Kinabalu lebih dikenal dengan Jesselton. Sabah pada saat dijajah oleh Inggris lebih dikenal dengan Borneo Utara (North Borneo), sebagai salah satu wilayah 
British Crown Colony (Zaini Othman

\& Saat Awang Damit, 2011: 9).

Islam pertama kali masuk di wilayah Sabah diperkirakan menjelang akhir abad ke-15 melalui pedagang Arab dan India dan juga hasil dari pengembangan dakwah Islam dari Kesultanan Melayu Brunei dan Kesultanan Sulu. Pihak Kesultanan Sulu telah bertanggungjawab dalam mengislamkan komunitas Melayu Sabah pada sekitar abad ke-17 M (Dokument Gezetir, JKNG, 2012: 26). Kemudian disusul masuknya saudagar muslim dari Sulawesi dan Sumatera. Mereka mendakwahkan Islam dimulai dari wilayah Lahad Datu. Hal ini dapat dibuktikan dari manuskrip dalam bahasa Ida'an yang menggambarkan kedatangan Islam berawal di wilayah Lahad Datu Sabah. Di antara nama-nama penyebar Islam di wilayah Sabah yaitu; Mandur Syari menyebarkan Islam khusus di Daerah Ranau; Zaini al-Palembangi menyebarkan Islam khusus di daerah Lahad Datu. Para saudagar Muslim yang masuk ke Sabah kemudian berasal dari Sulu; Brunei dan Indonesia di daerah- daerah lain di Sabah seperti Sandakan, Tawau, dan Lahad Datu. Mereka pada mulanya berinteraksi dan menjalin kontak dagang dengan penduduk tempatan. Di samping itu, interaksi yang intens antar saudagar dan penduduk tempatan, akhirnya penduduk lokal mencoba menyerap nilai-nilai agama yang dianut oleh para saudagar, yaitu dengan cara memeluk Islam.

Persebaran Islam dari Brunei ke Sabah terjadi pada era Sultan Bolkiah (berkuasa 1485-1524 M). Pada masa sultan Bolkiah berkuasa mengalami puncak kejayaan, karena perluasan pengaruhnya bukan saja di wilayah Borneo (Brunei), tetapi juga meliputi gugusan kepulauan Sulu di Filipina Selatan dan Pantai Barat Sabah (Pg. Mohammad bin Pg Abdurrahman, 2003: 104). Islam semakin berkembang terutama semenjak Malaka sebagai pusat penyebaran dan kebudayaan Islam, jatuh ke tangan Portugal (1511) yang menyebabkan banyak ahli dalam bidang agama pindah ke Brunei Darussalam, selanjutnya mempengaruhi kawasan Sabah dan Sarawak. Pada masa pemerintahan 
Sultan Bolkiah (sultan ke-5) yang wilayah kekuasaannya meliputi Suluk, Selandung, Borneo, kepulauan Sulu, Kepulauan Balabac, Pulau Banggi, Pulau Balambangan, Matanani dan utara Pulau Palawan sampai ke Manila menjadikan perkembangan Islam semakin luas dan nyata.

Tulisan ini akan mengupas tentang kapan dan dari mana Islam masuk ke Sabah Malaysia, apa saja bukti-bukti historis dan sosiologisnya, serta bagaimana perkembangan Islam terkini di Sabah Malaysia.

\section{Desain Penelitian}

Penelitian ini menggunakan pendekatan studi perpustakaan (library research) dan kajian lapangan (field research). Kajian perpustakaan digunakan untuk mendapatkan data-data tertulis yang berkenaan dengan objek penelitian, sedangkan kajian lapangan digunakan untuk mendapatkan datadata langsung dari objek sasaran penelitian.

Teknik pengumpulan data dalam penelitian ini dimulai dari akumulasi data, verifikasi data, interpretasi data dan dilanjutkan dengan penulisan. (John Funston [Editor], 2001: 11). Data dikelompokkan menjadi dua jenis, yaitu data primer dan sekunder. Jika dilihat dari segi subjek penelitian, maka penelitian ini masuk penelitian sejarah dan sejarah sosial keagamaan, sebab subjek penelitian sejarah itu adalah sosial, keagamaan, ekonomi dan gejala alam (Dudung Abdurrahman, 1999: 7). Data-data yang terkumpul baik dari data primer maupun data sekunder selanjutnya dilakukan analisis. Setelah semua kegiatan pengkajian data dan analisis data selesai dilanjutkan dengan laporan penyelidikan dalam bentuk laporan penelitian. Teknik analisis menggunakan pendekatan analisis sosio-historis dan Content analisis.

\section{Gambaran Umum tentang Sabah}

Negeri bagian Sabah memiliki luas daratan 73.620 KM. Kemudian Sabah terbagi dalam 7 kawasan (regional), yaitu: (1) West Coast (North), (2) West Coast (South), (3) Keningau, (4) kawasan Tawau (5) Kawasan Lahad Datu, (6) Kawasan 
Beaufort, dan (7) kawasan Sandakan.

Selanjutnya tujuh regional tersebut membawahi 25 District (daerah) yaitu: Beaufort; Keningau; Kinabatangan; Kota Belud; Kota Kinabalu; Kota Marudu; Kuala Penyu; Kudat; Kunak Labuk; Sugut; Lahad Datu; Papar; Penampang; Pensiangan; Pitas; Ranau; Sandakan; Semporna; Sipitang; Tambunan; Tawau; Tenom; Tongod; dan Tuaran. Di setiap Negeri Bagian terdapat beberapa Daerah. Daerah adalah merupakan satu bagian kawasan pemerintahan di bawah negeri Bagian di Malaysia (Dokumen Gazetir, 2012: 6).

Gambar 1. Peta Negara Malaysia

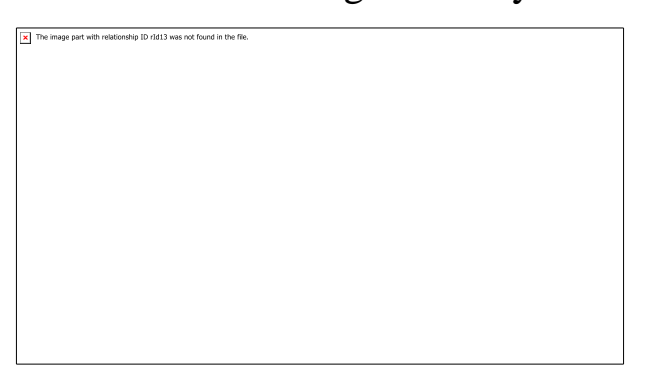

Secara rinci 7 kawasan (regional) dan 25 distrik di Sabah tersebut adalah: (1) West Coast (North), meliputi distrik Tuaran, Ranau, Kota Belud, Kota Marudu, Kudat, dan Pitas; (2) West Coast (South), meliputi distrik Kota Kinabalu, Penampang, Papar, dan
Putatan; (3) Keningau, meliputi distrik Keningau, Tambunan, Tenom, dan Pensiangan; (4) Kawasan Tawau, meliputi distrik Tawau, Semporna; (5) Kawasan Lahad Datu, meliputi distrik Lahad Datu, Kunak; (6) Kawasan Beaufort, meliputi distrik Beaufort, Kuala Penyu, Sipitang; dan (7) Sandakan, meliputi distrik Sandakan, Labuk Sugut, Kinabatangan, dan Tongod.

Persebaran Islam terutama di wilayah Pantai Barat dan timur berkembang di sebagian besar District (daerah-daerah) di Sabah, yaitu Beaufort, Keningau, Kinabatangan, Kota Belud, Kota Kinabalu, Kota Marudu, Kuala Penyu, Kudat, Kunak Labuk, Sugut, Lahad Datu, Papar, Penampang, Pensiangan, Pitas, Ranau, Sandakan, Semporna, Sipitang, Tambunan, Tawau, Tenom, Tongod, dan Tuaran. Di setiap Negeri Bagian terdapat beberapa Daerah. Daerah adalah merupakan satu bagian kawasan pemerintahan di bawah negeri Bagian di Malaysia. 


\section{Masuknya Islam di Sabah Malaysia}

Islam masuk ke Sabah diperkirakan pada abad ke-10 M, berdasarkan datangnya kapal dagang Arab yang telah masuk ke Canton, China dari Mendoro (Ma-i) yaitu satu tempat di kepulauan Sulu tidak jauh dari Sabah pada tahun $982 \mathrm{M}$. Dengan ini dipercayai bahwa orangorang Islam telah bertempat tinggal di tempat tersebut dan mempengaruhi orang tempatan memeluk agama Islam pada akhir abad ke-14 hingga abad ke-15. Fakta ini diperkuat dengan adanya terdapat batu nisan orang-orang Islam di Bud Dato, Jolo tahun 1310 M. (Datuk Gamdin Buyong, 1995: 1). Berikutnya Agama Islam berkembang di Kepuluan Sulu oleh seorang ulama yang berasal dari Arab bernama Syarif Aulia Karim alMakhdum pada tahun $1380 \mathrm{M}$ dan berkembang pula di pulau Mindanao oleh seorang ulama yang berasal dari Arab bernama Syarif Muhammad pada tahun 1575 M. Dari tempat inilah kemudian Islam berkembang sampai ke pesisir pantai Timur Sabah, khususnya di kawasan
Kinabatangan dan Lahad Datu dan terus meluas sampai ke kawasan Pantai Barat Sabah (Datuk Gamdin Buyong, 1995: 1).

Lebih lanjut dijelaskan bahwa Islam telah berada di Sabah setidaktidaknya sebelum tahun-tahun terakhir dari tahun 1300. Hal ini didasarkan bukti tertulis dalam bahasa Melayu yang ditemukan di kampong Sapagaya, lahad Datu. Tulisan tersebut memberikan kemungkinan bahwa pengislaman di Teluk Darvel berasal dari seorang keturunan Melayu yang bernama Abdullah berasal dari Lahad Datu pada tahun 1408 M sebagai kelanjutan dari pengislaman yang dilakukan oleh Syarif Auliya alMakhdum sebelumnya yaitu pada tahun 1380 M. (Datuk Gamdin Buyong, 1995: 1). Manuskrip tersebut ditemukan tahun $1408 \mathrm{M}$ diperkirakan ditulis oleh penduduk Sabah yang telah mempelajari agama Islam terlebih dahulu. Dengan kata lain, penulisnya telah masuk Islam sekurang-kurangnya pada tahuntahun terakhir dari tahun $1033 \mathrm{M}$.

Islam masuk ke Sabah secara intensif terjadi pada abad ke $16 \mathrm{M}$, 
dimulai dari kawasan pantai Barat Sabah yaitu berasal dari kesultanan Brunei, karena kawasan tersebut semula bagian dari daerah kekuasaan Sultan Brunei. Persebaran Islam dari Brunei ke Sabah terjadi pada masa Sultan Bolkiah (berkuasa 1485-1524 M) karena beliau termasuk pemimpin yang sangat suka berpetualangan ke berbagai wilayah disamping mendakwahkan Islam juga memperluas daerah taklukan (daerah kekuasaan). Persebaran penduduk melayu Brunei secara bertahap bermigrasi ke kawasan pantai Barat Sabah, karena orang Brunei beragama Islam sekaligus persebaran Islam pun terjadi. (Pg. Mohammad bin Pg Abdurrahman, 2003: 104). Puncak kejayaan Islam di kesultanan Brunei adalah pada masa sultan Bolkiah berkuasa karena perluasan pengaruhnya bukan saja di wilayah Borneo (Brunei), tetapi juga meliputi gugusan kepulauan Sulu di Filipina Selatan dan Pantai Barat Sabah (John Funston, Edit, 2001: 11)

Islam masuk di wilayah Sabah yang lebih awal diperkirakan menjelang akhir abad ke-15 M melalui pedagang Arab dan India.
Namun, bukti sejarahnya luput dari penguraian para ahli sejarah. Bukti sejarah yang lebih menonjol justru memasuki abad ke 16 M., yaitu dimulai dari petualangan dari kesultannan Brunei yaitu sultan Bolkiah (berkuasa 1485-1524 M) untuk pengembangan dakwah Islam. Pihak Kesultanan Sulu juga punya andil dan bertanggungjawab dalam mengislamkan komunitas Melayu Sabah pada sekitar abad ke-17 terutama di kawasan pantai Timur Sabah. Kemudian di susul masuknya saudagar muslim dari Sulawesi dan Sumatra. Mereka mendakwahkan Islam dimulai dari wilayah Lahad Datu. Hal ini dapat dibuktikan dari manuskrip dalam bahasa Ida'an yang menggambarkan kedatangan Islam berawal di wilayah Lahad Datu Sabah. Diantara nama-nama penyebar Islam di wilayah Sabah yaitu, Mandur Syari menyebarkan Islam khusus di Daerah Ranau; Zaini al-Palembangi menyebarkan Islam khusus di daerah Lahad Datu.

Para saudagar Muslim yang masuk ke Sabah sebagian juga berasal dari kesultanan Sulu pada abad ke17 M. Secara geografis, 
lokasi Sabah sangat dekat dengan Pulau Sulu di Filipina Selatan. Bisa ditempuh dalam waktu satu jam dengan perahu. Ini pula yang menyebabkan, sampai hari ini, warga Filipina Selatan, khususnya yang tinggal di Sulu sering pulang pergi ke Sabah. Pulau Sulu adalah daerah di kepulauan Sulu yang di dalamnya berdiri Kesultan Sulu dengan pusat pemerintahannya di Jolo. Pulau Sulu luas wilayahnya $1600 \mathrm{KM}$ dibawah sistem kesultanan Islam Sulu sejak tahun 1450 M. Pada masa kegemilangan Kesultanan Sulu wilayahnya hingga menjangkau dari Mindanao hingga Sabah (North Borneo). Penduduk Asli Pulau Sulu adalah Suku Bajau; Suluk; tausog; Banguingui dimana bahasanya campuran antara bahasa MelayuTagalog.

\section{Perkembangan Islam di Sabah masa Kesultanan}

Sabah sejak awal abad ke- 17 M bercorak kesultanan, tetapi tidak berada dalam kesultanan yang berdiri sendiri, namun Sabah saat itu menjadi bagian dari wilayah Kesultanan Brunei. Pada saat di bawah kendali pemerintahan Kesultanan Brunei, kedaulatan atas tanah dan penduduk di Sabah berada dalam kekuasaan Sultan. Namun, pembagian hak-hak otonomi tradisional telah memberikan kekuasaan yang luas kepada kaum bangsawan Brunei yang tinggal di Sabah untuk mengurusi tanah dan pengikut mereka (Pangeran Fatimah Binti Datuk Sidek, 2011: 72). Pada saat Sabah di bawah kekuasaan Kesultanan Brunei, kawasan ini dibagi menjadi beberapa wilayah, dan setiap wilayah diperintah oleh para pangeran Brunei yang menjadi pembesar-pembesar di Sabah. Sistem pemilikan tanah dalam pemerintahan Brunei di Sabah dapat di bagi dalam tiga kategori, yaitu: (1) harta kerajaan, (2) harta kuripan, dan (3) harta tulin atau pesaka (Pangeran Fatimah Binti Datuk Sidek, 2011: 72). Kepemilikan harta Tulin atau pesaka, disandarkan pada kepemilikan pangeran secara personal. Jika pangeran pemilik harta tulin meninggal, maka harta tersebut diwarisi oleh keturunannya.

Kesultanan Melayu Brunei punya peran penting dalam proses 
masuknya Islam di Sabah. Berkaitan dengan peran Kesultanan Brunei dalam menyebarkan Islam di kawasan pantai Barat Sabah pada abad ke $16 \mathrm{M}$, saat itu dipimpin langsung Sultan Bolkiah (berkuasa 1485-1524 M). Sultan Bolkiah sangat gemar melakukan petualangan untuk memperluas kekuasaan sekaligus menyebarkan Islam ke berbagai wilayah setelah runtuhnya Malaka ke tangan Portugis tahun 1511 M. (Seri Maharaja Dato Dr. Haji Awang Mohd. Jamil Al-Sufri, 1997: 186). Pada masa sultan Bolkiah berkuasa, Brunei mengalami puncak kejayaan, karena perluasan pengaruhnya bukan saja di wilayah Borneo (Brunei), tetapi juga meliputi gugusan kepulauan Sulu di Filipina Selatan dan Pantai Barat Sabah. karena kawasan tersebut semula bagian dari kekuasaan Sultan Brunei. Persebaran penduduk melayu Brunei secara bertahap bermigrasi ke kawasan pantai Barat Sabah, karena orang Brunei beragama Islam sekaligus persebaran Islam terjadi.

Melayu Brunei di Sabah dalam proses persebaran Islam, pada awalnya di pinggiran pantai Barat
Sabah selanjutnya tersebar juga di Pantai Timur yang lebih dikenal dengan sebutan Kampong ayer (kampung Air). Berdasarkan data statistik tahun 1990 terdapat 239 buah kampong air di negeri Sabah. 126 kampung terletak di pantai Timur dan sisanya 113 kampung terletak di pantai Barat Sabah. Karakteristik wilayah sepanjang 900 KM menjadi tempat bermukimnya penduduk melayu muslim Brunei dan etnik lainnya. Penduduk negeri Sabah yang bermukim di kampung air sekitar 139.985 jiwa (9.5\%). (Abdul Latif Bin Ibrahim, 2011: 6). Mereka berbaur dengan etnik lain, yaitu suku Kadasan-dusun, Bajau, Murut, Rungus, Iranum, Bisaya, Tatana, Lun Dayeh, Tindal, Tobilung, Kimarangang, Suluk, Ubian, Tagal, Timogun, Nabay, Kedayan, Minokok, Mangka'ak, Lobu, Binggi, Tidong, Ida'an, Begahak, Talatang, Tinagas, Banjar, Gana, Tombonuo, Dumpas, Peluan, Baukan dan Bugis. Masing-masing suku memliki tradisi lisan tersendiri untuk mengurai tentang migrasinya mereka ke Sabah (D.S Ranjith Singh, 2003: 5). 
Kedaulatan atas tanah dan penduduk di Sabah berada dalam kekuasaan Sultan Brunei selama beberapa kurun waktu. Namun, pembagian hak-hak otonomi tradisional telah memberikan kekuasaan yang luas kepada kaum bangsawan Brunei yang tinggal di Sabah untuk mengurusi tanah dan pengikut mereka (Pangeran Fatimah: 2011). Pada saat itu Sabah mulai di bagi menjadi beberapa wilayah, dan setiap wilayah di perintah oleh para pangeran Brunei yang menjadi pembesar-pembesar di Sabah. Namun pada pertengahan abad ke 17 M, terjadi perebutan kekuasaan di kesultanan Brunei tepatnya tahun 1662 M, sehingga sultan Brunei minta bantuan kepada Sultan Sulu untuk memenangkan peperangan dalam internal kekuasan. Setelah kemenangan berpihak kepada Sultan Brunei Muhyiddin, sebagai kompensasinya adalah Sultan Muhyiddin menyerahkan kawasan timur laut Brunei kepada Sultan Sulu, akibatnya Sabah diperintah oleh dua kekuasann itu, Kesultanan Brunei dan Kesultanan Sulu.
Kesultanan Sulu juga punya andil dalam proses masuk dan berkembangnya Islam di Sabah terutama komunitas Melayu, Bajau dan Murut sekitar abad ke-17 di kawasan pantai Timur Sabah. Pada masa kegemilangan Kesultanan Sulu wilayahnya hingga menjangkau dari Mindanao hingga Sabah (North Borneo). Penduduk Asli Pulau Sulu adalah Suku Bajau; Suluk; tausog; Banguingui di mana bahasanya campuran antara bahasa MelayuTagalog. Di kawasan pesisir pantai Sabah perdagangan lebih dikuasai oleh pedagang-pedagang Islam dan disalurkan melalui pusat kekuasaan Kesultanan Brunei di kawasan barat selatan dan Kesultanan Sulu proses berkembangnya Islam di kawasan utara dan juga di kawasan Pantai Timur, muara Batang Kayan yang menjalankan pengaruhnya sekurangkurangnya hingga ke utara termasuk Lahad Datu pada masa itu (Datuk Gamdin Buyong, 1995: 2). Kesultanan Sulu melakukan ekspansi penyebaran Islam kepada penduduk lokal Sabah sekitar abad ke-17 M karena disebabkan muslim Sulu sering ditekan dan serang oleh 
koloni Spanyol (1521-1898 M) di Philipina Utara (Luzon, Visayas) hingga Selatan (Mindanao, Sulu, Basilan, Tawi-tawi Cota-Bato) kemudian berlanjut masuknya koloni Amerika tahun 1898-1946. Sebagian muslim Mindanao dan Sulu melakukan migrasi ke pantai Timur Sabah untuk mendapatkan kehidupan yang lebih baik dan aman (Black, 2011: 141).

Keragaman kelompok etniklinguistik muslim Sulu dan Mindanao tidak menjadikan mereka seperti kelompok yang terpisah, mengingat terdapat banyak kesamaan dari segi bahasa yang mereka gunakan dan agama yang mereka anut. Sebagai contoh bahasa Maguindanao dan Marano memiliki kemiripan dari segi penyebutan dan makna yang terkandung dalam kosakata, sehingga kedua pengguna bahasa ini saling memahami. Kemudian banyak pula kedekatan secara linguistik antara dialek yang digunakan sebagian orang Islam dan Katolik seperti bahasa Tausog (wilayah selatan) yang hampir sama dengan bahasa Tagalog dan Visayan (ada di wilayah Utara). Kedua bahasa ini digunakan secara luas (massive) oleh mayoritas pemeluk Katolik. Menurut pendapat ahli bahasa modern, semua bahasa dan dialek tersebut ternyata berasal dari rumpun keturunan yang sama. Melayu Muslim Sulu dan Mindanao meski menyandang kelompok minoritas di Filipina, namun mereka adalah komunitas agama terbesar kedua setelah pemeluk Katolik. Posisi seperti ini membuat komunitas melayu Muslim Sulu dan Mindanao penting bagi perkembangan sosiopolitik di negara Filipina pasca kolonialisasi Spanyol dan Amerika.

Berdirinya kekuasaan Sultan Sulu dimulai sejak tahun $1450 \mathrm{M}$ yang dipimpin oleh Sultan Syarif Abu Bakar, sampai akhirnya kekuasaan ini berakhir pada tahun 1915 M seiring kuatnya tekanan politik kekuasaan kolonial Amerika. Hal ini berarti kekuasaan kesultanan Sulu bisa bertahan hingga 500 tahun. Namun, sebagian ahli sejarah percaya bahwa kesultanan sebagai suatu sistem baru mengalami kejatuhan sejak tahun $1936 \mathrm{M}$. Ketika persemakmuran menolak untuk mengakui setiap pewaris yang 
menentang kekuasaan Sultan Jamalul Kiram II terakhir berkuasa. Formasi komunitas politik yang terorganisir sebagai hasil dari unifikasi banua (komunitas) yang terpusat memberikan sumbangan berharga bagi suku Tausog di Kesultanan Sulu. Kesultanan Sulu bukan hanya melingkupi masyarakat suku Tausog, tetapi juga mengendalikan beberapa suku lainnya seperti suku Samal, Yakanes, Badjau yang muslim, termasuk suku-suku yang terletak di wilayah Zamboanga dan Basilan (Charmen A Abu Bakar, 1993: 199). Kesultanan Sulu juga berperan dalam mengambil legitimasi kekuasaan dari tradisi sebagai bagian dari wilayah Daar al-Islam, yaitu wilayah yang berupaya untuk menerapkan syariat Islam dan hukum Islam. Ketidakberdayaan Muslim Sulu dalam melawan dari tekanan koloni Spanyol hampir 370 tahun, sebagian penduduknya melakukan migrasi ke pantai Timur Sabah.

\section{Perkembangan Islam di Sabah Masa Kolonial}

Pada awalnya ketika Malaysia Merdeka, Sabah belum menjadi bagian negeri persekutuan Malaysia. karena Sabah memerdekakan diri dari kolonialisme Inggris pada tanggal 31 Agustus 1963. Kemudian Perdana Menteri Malaysia Tunku Abdul Rahman datang ke Sabah untuk mengajak Sabah dan Sarawak turut bergabung dengan pemerinthaan Malaysia, selain Singapura yang telah terlebih dulu bergabung untuk berada dalam Negara Persekutuan. Tawaran dar Perdana Menteri Malaysia Tunku Abdul Rahman ini diterima oleh pemimpin-pemimpin Borneo Utara (Sabah) dan Sarawak. Namun, dalam perjanjian itu dibuat beberapa syarat tepatnya terdapat 20 Isi Perjanjian antara Tunku Abdul Rahman selaku Perdana Menteri dengan tokoh-tokoh penting Sabah dan Sarawak yang mewakili seluruh etnik yang ada di wilayah tersebut. Perjanjian itu disepakati bersama dan ditandatangani pada tanggal 16 September 1963 menandai bergabungnya Sabah dengan Malaysia.

Dalam perjanjian kesepakatan antara Perdana Menteri Tunku Abdul Rahman dengan tokoh-tokoh penting 
Sabah itu, di antara beberapa syarat dalam 20 butir kesepakatan tersebut, mengandung substansi bahwa Sabah menurut Pasal 4 (1) dan Pasal 5 (1) menyatakan Sabah adalah sebuah Negara. Selanjutnya dalam pasal 18 tertulis tentang pimpinan Sabah dengan nama ketua negeri, disebut bahwa gelar Ketua Negerinya adalah Yang Dipertuan Negara, bukan Yang Dipertuan Negeri. Oleh karena itu, sejak Sabah memerdekakan diri dari kolonialisme Inggris pada tanggal 31 Agustus 1963 - 16 September 1963, pada dasarnya Sabah adalah sebuah Negara merdeka yang berdiri sendiri. Namun Sabah, Sarawak, dan Singapura akhirnya melalui Perjanjian yang telanh ditandatangani pada tanggal 16 September 1963 menandai bergabungnya Sabah dengan Malaysia.

Persebaran Islam dari Kesultanan Sulu kepada penduduk lokal Sabah sekitar abad ke-17 M sebagai akibat dari tekanan dan serangan koloni Spanyol (1521-1898 M) di Philipina Utara (Luzon, Visayas) hingga Selatan (Mindanao, Sulu, Basilan, Tawi-tawi Cota-Bato).
Sebagian muslim Mindanao dan Sulu melakukan migrasi ke pantai Timur Sabah untuk mendapatkan kehidupan yang lebih baik. Secara geografis, lokasi Sabah sangat dekat dengan Pulau Sulu di Filipina Selatan. Bisa ditempuh dalam waktu satu jam dengan perahu. Ini pula yang menyebabkan, sampai hari ini, warga Filipina Selatan, khususnya yang tinggal di Sulu sering pulang pergi ke Sabah. Bagi mereka yang tinggal di Lahad Datu, sekitar 450 kilometer dari Kinabalu, komunitas muslim Sulu bisa dilakukan pulang setiap hari.

Pada masa kolonial, Sabah berada di bawah kekuasaan Syarikat Berpiagam Borneo Utara British BNBCC (British North Borneo Chartered Company) dari $1881 \mathrm{M}$ sehingga pendudukan tentera Jepang pada tahun 1942. Setelah terjadinya perang Dunia Kedua, Sabah menjadi wilayah jajahan Inggris. Sampai pada akhirnya British melakukan pembentukan adminstrasi untuk mencapai pemerintahan otonom sendiri. Pada 16 September 1963, Sabah bersama Sarawak, Singapura dan Tanah Melayu menjadi 
Persekutuan Malaysia. Pemerintahan

Syarikat Berpiagam Borneo Utara

British (BNBCC atau British North

Borneo Chartered Company)

berakhir pada tahun 1946 dan

akhirnya Sabah menjadi jajahan

Inggris. Penyerahan Borneo Utara

ini, oleh pihak BNBCC telah melanggar syarat "Perjanjian Sewa

Wilayah North-Borneo" yang telah disetujui kedua belah pihak antara Sultan Sulu dan Mr. Barron de Overback \& Mr. Alfred Dent, yang telah membentuk Syarikat Berpiagam dan akhirnya wilayah North-Borneo di tempatkan di bawah kekuasaan jajahan Inggris. Namun, kedaulatan North-Borneo masih berada di atas kuasa Kesultanan Sulu. Kekuasan Inggris atas NorthBorneo atau Sabah hanyalah sebagai Proctorate \& Administrator sehingga keikutsertaannya dalam Persekutuan Malaysia beserta Sarawak, dan Singapura.

Pada waktu Sabah memperoleh kemerdekaan dari Inggris melalui Malaysia pada 16 September 1963 M, terangkum 20 poin perjanjian penyertaan Sabah dalam persekutuan Malaysia tidak terdapat adanya agama resmi bagi Sabah. Sehingga para pemimpin Islam Sabah semakin terdesak untuk mencari jalan dan langkah-langkah baru untuk terwujudnya persatuan Islam Sabah. Agar usaha untuk menjadikan agama Islam sebagai agama resmi negeri segera terwujud karena agama Islam seperti terdapat dalam pelembagaan Malaya sebagai agama resmi tidak berlaku di Sabah (Datuk Gandim Buyong, 1995: 18-19).

Keputusan tersebut sangat mengkhawatirkan para pemimpin Islam di Sabah yang mendorong mereka untuk segera menggabungkan semua persatuan Islam di Sabah ke arah mengagungkan keberadaan Islam di Sabah. Dalam Majlis Peresmian Pertandingan (musabaqah) Membaca Kitab Suci al-Qur'an tingkat negeri Sabah yang diadakan Persatuan Islam Putatan (PIP) pada 13 Oktober 1968. PIP (Persatuan Islam Putatan) sekali lagi menyuarakan pandangannya agar semua organisasi persatuan Islam di Sabah yang masih terkotak-kotak dalam organisasi yang beragam, agar bergabung menjadi persatuan yang besar dan kokoh 
untuk dapat menangani masalah yang timbul akibat dari "20 Poin" yang tidak memberikan perhatian kepada agama Islam (Emin Madi, 2009: 19).

Beberapa orang tokoh yang hadir dalam Majlis tersebut seperti penasehat politik Tun Datu Mustapha bin Datu Harun, Syed Kechik bin Syed Muhammad (Datuk) dan Menteri keuangan Negeri Habib Abdul Rahman bin Habib Mahmud (Datuk) memperlihatkan komitmen mereka untuk bersama-sama menangani masalah tersebut. Di sekitar tahun 1950 hingga awal tahun 1960 beberapa persatuan Islam telah muncul di negeri Sabah. Antara lain, Persatuan Islam Putatan (PIP) yang diketuai oleh Imam Ahmad Mus Haji Ismail, Persatuan Islam Sabah (PIS) yang dipimpin oleh Tuan Haji Yusof Shamsuddin dan Persatuan Islam Tawau (PIT) di bawah pimpinan OKK Zainal Kerahu. Penyebab dari munculnya persatuan-persatuan tersebut karena adanya kesadarankesadaran di kalangan pemimpin Islam ketika itu untuk bersatu padu jika ingin mengokohkan kedudukan agama Islam dan mencapai kemajuan (Ustadz Najion Jamil, 2010: 14).
Melalui kesadaran-kesadaran yang telah disebutkan di atas dijadikan langkah awal bagi gerakan menggabungkan seluruh persatuan Islam yang terdapat di Borneo Utara supaya menjadi lebih kuat dan maju. Untuk mewujudkan usaha mempersatukan umat Islam itu mereka para pemimpin Islam menjemput Datu Haji Mustapha bin Datu Harun untuk mengusahakan dilaksanakannya Majlis Permusyawarahan mengenai hasrat murni itu bertempat di kediaman Tuan Haji Yusof Shamsuddin di Kampung Sembulan. Tetapi sangat disayangkan rencana itu tergendala karena Datu Haji Mustapha bin Datu Harun ketika itu terlibat secara langsung dalam proses pembentukan Malaysia yang digagas oleh Tunku Abdul Rahman (Ustadz Najion Jamil, 2010: 14). Setelah Sabah bergabung dengan Malaysia pada 16 September 1963, kenyataannya jumlah umat Islam di Sabah jauh lebih kecil dibandingkan dengan jumlah penganut non-muslim, bahkan sebelum merdeka pada tahun 1960 jumlah umat Islam 37,96\% atau 172.324 orang dari penduduk Sabah 
yang berjumlah 454.421 orang. Sementara penganut pemeluk agama Kristen $45.5 \%$ dan selebihnya menganut agama pagan atau animisme (Emin Madi, 2009: 14-15).

\section{Perkembangan Islam di Sabah Terkini dan Peran USIA}

Memasuki fase abad ke $20 \mathrm{M}$ tokoh-tokoh Islam Sabah mulai menggalang kekuatan untuk mengembangkan Islam ke berbagai daerah di Sabah atau North Borneo hingga ke wilayah pedalaman. Langkah-langkah yang mereka lakukan agar efektifitas dan jangkauan dakwah lebih fokus, maka mereka membentuk organisasi Islam sehingga muncullah 3 organisasi terkemuka, yaitu: (1) Persatuan Islam Putatan (PIP) yang didirikan oleh Haji Ag Sahari Abd. Latif, (2) Persatuan Islam Tawau (PIT) yang dipelopori oleh Orang Kaya-kaya (OKK) Zainal Kerahu, dan (3) Persatuan Islam Sabah (PIS) yang dimotori Datuk Haji. Mohd Kassim Bin Haji Hasyim (Emin Madi, 2009: 10-11).

Lahirnya tiga organisasi Islam ini bertujuan untuk memperjuangkan nasib umat. Islam beserta hak-hak mereka sebagai warga negara (Nur A'thiroh Masyaa'il Tan Binti Abdullah \& Abdul Imam Basirun 2014: 47). Ketiga organisasi yang bergerak secara terpisah ini tidak bertahan lama karena tidak memiliki kekuatan dalam mempersatukan umat Islam. Karena itu muncul gagasan untuk menyatukan ketiga gerakan Islam ini menjadi sebuah organisasi yang lebih kuat. Pada tahun 1968 Tun Datu Haji Mustapha bin Datu Harun mengadakan pertemuan dengan ketiga-tiga pimpinan persatuan Islam yaitu Datuk Haji Awang Sahari yang menjadi ketua PIP (Persatuan Islam Putatan), Orang Kaya-kaya (OKK) Zainal Kerabu ketua PIT (Persatuan Islam Tawau) dan Datuk Haji Muhammad Kassim bin Haji Hashim ketua PIS (Persatuan Islam Sabah) di kediaman Tun Datu Haji Mustapha bin Datu Harun di Tanjung Aru khusus untuk membicarakan kedudukan umat Islam di Sabah (Emin Madi, 2009: 17).

Pada masa akhir Kongres 16 Agustus 1969 menjadi hari yang bersejarah dalam pertubuhan USIA 
karena pada hari itulah pertubuhan USIA diwujudkan dari kira-kira 300 peserta kongres termasuk 179 perwakilan dan 80 pemerhati dari seluruh Sabah. Melalui Kongres inilah persetujuan dicapai untuk menubuhkan (mendirikan) United Sabah Islamic Association (USIA). Tun Datu Haji Mustapha bin Datu Harun diangkat menjadi Yang diPetuanya (ketua) yang pertama. Pendirian USIA itu kemudian didaftarkan pada 10 Oktober 1969. Sedangkan saat ini USIA diketuai oleh Tun Datu Seri Panglima Haji Sakaran bin Dandai (Emin Madi, 2009: 15). Menurut pendapat Datuk Haji Din pengusulan awal bagi berdirinya USIA dikemukakan oleh Tuan Haji Lokman Musa yang ketika itu memegang jabatan Pengarah Pengajaran Islam Sabah untuk mewakili Jawatan kuasa Penaja pada hari pertama persidangan. Usulan itu mendapat dukungan penuh dari peserta Kongres (Emin Madi, 2009: 19). Dengan demikian, pada 16 Agustus 1969 lahir organisasi Islam yang unggul di Sabah, yaitu Pertubuhan Islam Seluruh Sabah untuk melaksanakan agenda memperjuangkan nasib masyarakat Islam serta memartabatkan agama Islam yang sebelumnya hanya dicoba diperjuangkan oleh beberapa persatuan Islam saja, terutama di antaranya Persatuan Islam Putatan, Persatuan Islam Tawau, dan Persatuan Islam Sabah.

Ketiga organisasi baik PIT, PIS, dan PIP juga sepakat menunjuk Tun Datuk Haji Mustapa Bin Datuk Harun untuk mencari jalan keluar bagi penndirian organisasi dakwah yang lebih unggul. Berdasarkan kesepakatan tersebut, maka pada tanggal 16 Agustus 1969 lahirlah Organisasi Islam Seluruh Sabah dengan nama United Sabah Islamic association (USIA) yang dihadiri lebih dari 300 orang Islam dari seluruh Negeri Sabah. Organisasi Dakwah USIA merupakan salah satu organisasi dakwah yang terkenal di negeri Sabah, yang mempunyai kekuatan luar biasa untuk mengembangkan dakwah Islam. Dorongan dari segi inilah menjadikan USIA melancarkan gerakan dakwah secara besar-besaran ke berbagai wilayah Sabah dan memberi pengaruh besar bagi 
masyarakat muslim dan perkembangan Islam di Sabah (Nur A'thiroh Masyaa'il Tan Binti Abdullah, 2014: 1)

Cita-cita besar organisasi USIA adalah menjadikan agama Islam sebagai agama resmi di Sabah. Sebagai pimpinan organisasi dakwah, Tun Datuk Haji Mustapha telah memfokuskan gerakan dakwahnya untuk mengislamkan masyarakat non-Muslim sebanyak mungkin dan diluncurkan secara besar-besaran di setiap cabang daerah masing-masing (Emin Madi, 2009: 40-42). Organisasi Islam ini berhasil membangun kekuatan umat Islam baik secara kuantitas maupun kualitas. Hal ini dibuktikan dengan munculnya pemimpin-pemimpin dan pejabat pemerintah termasuk menteri-menteri dan wakil-wakil rakyat yang berasal dari hasil binaan organisasi USIA.

Sejak bergabungnya Sabah dengan Malaysia tahun 1963 telah membawa semangat baru bagi perkembangan Islam di Sabah. Karena Tun Datu Haji Mustapha diangkat sebagai Ketua Menteri Sabah (setingkat Gubernur).
Optimisme para tokoh Islam pada masa awal 1970-an ini terus meningkatkan perkembangan dakwah Islam di Sabah.

Selanjutnya Tun Datu Haji Mustapha diangkat menjadi Yang diPetuanya (ketua) yang pertama, menyampaikan 11 dasar perjuangan USIA, yaitu:

1. Memajukan kepentingankepentingan agama Islam.

2. Memperteguh tauhid kepada Allah sebagai dasar pendidik diri supaya menjadi baik dan tinggi budi pekerti serta bebas pikirannya di antara satu sama lain.

3. Mengadakan segala kemudahankemudahan pengajian dan pengetahuan dalam agama Islam di kalangan semua kaum dan ugama.

4. Mendirikan dan menjaga urusan masjid, surau, madrasah, wakaf, tanah-tanah perkuburan, dan lainlain perkara yang bersangkut paut dengan orang-orang Islam di seluruh Sabah.

5. Mengambil langkah-langkah yang perlu untuk mengelola pemungutan zakat dan fitrah serta 
pembagiannya secara lebih lancar (sistimatik) (dan dapat persetujuan kerajaaan).

6. Mengadakan bantuan kepada orang-orang Islam di seluruh Sabah yang berada dalam kesusahan dan faedah-faedah kematian kepada anggota (USIA) dan juga orang-orang musafir.

7. Mengadakan Jawatan kuasa berkenaan agama, kebajikan, persekolahan, taman bacaan, penerangan, kaum ibu, dan lainlain perkara yang dipikirkan mustahak, termasuklah perkaraperkara yang tidak bertentangan dengan agama Islam dan sesuai mengikut keperluan semasa.

8. Memberi penerangan kepada anggota USIA (United Sabah Islamic Association) yang hendak menunaikan ibadah haji ke Mekah dengan kerjasama Kerajaan dan Pejabat Urusan Haji di Pulau Pinang.

9. Mengadakan perhubungan dan kerjasama yang lebih rapat dengan persatuan-persatuan Islam di luar Sabah atau lain-lain pertubuhan di mana-mana tempat demi kemajuan Islam.
10. Menjalankan segala daya usaha untuk menanam modal bagi apaapa perniagaan yang akan mendatangkan hasil kepada USIA (United Sabah Islamic Association).

11. Menjalankan usaha yang penting supaya tercapai tujuan organisasi (Emin Madi, 2009: 22-24).

\section{United Sabah Islamic} Association (USIA) merupakan NGO (Non-Govermental Organization) yang berperan besar di negeri Sabah dalam menyebarkan agama Islam serta berperan dalam usaha pengislaman yang dilaksanakan terutama kaum asli yang terdapat di pedalaman Sabah. Selain itu, USIA juga membimbing masyarakat Muslim dengan berbagai macam program dakwah kepada Muslim dan bukan Muslim. Dalam masa yang sama, USIA juga menyediakan kelas-kelas bimbingan agama kepada saudara baru (mualaf) dan masyarakat Muslim lainnya. Langkah ini digariskan dalam tujuan organisasi USIA adalah untuk mengenali, mendalami, memahami, menghayati seterusnya mengamalkan 
cara hidup Islam yang terintegrasi dalam konteks kehidupan seharian mereka.

Tun Datu Haji Mustapha sebagai Ketua Menteri Sabah menggiring perkembangan Islam dan penganutnya mendapat kedudukan yang sejajar dengan kelompok etnis lainya di negeri Sabah dalam berbagai aspek. Ia telah menjalankan usaha-usaha tersendiri bagi merubah citra Islam dan pemeluknya di Sabah agar non-muslim tertarik untuk memeluk Islam. Salah satu langkah awal Tun Datu Hj Mustapha dalam kegiatan dakwah ialah mengintensifkan kegiatan-kegiatan berbentuk keagamaan di institusi pemerintahan dan kelompokkelompok masyarakat.

Perubahan besar terjadi di Sabah bukan saja dalam sejarah perkembangan Islam tetapi juga masuk dalam ranah sejarah politik di negeri ini. Hal ini tentu tidak bisa dilepaskan dari peran berdirinya USIA di bawah kempimpinan Tun Datu $\mathrm{Hj}$ Mustapha sebagai ketua Menteri Sabah sekaligus sebagai Ketua USIA. Gerakan dakwah berjalan lancar dan USIA berhasil mengislamkan puluhan ribu penduduk negeri ini terutamanya masyarakat suku kaum Kadazan/ Dusun, Murut, Rungus dan kaumkaum lain yang tidak mempunyai pegangan agama (Wawancara: Iyen Yatim, 12-10-2017). Hakikat dari kegiatan dakwah USIA tersebut menjadi faktor yang dominan dalam sejarah perkembangan Islam dan politik di Sabah setelah berdirinya USIA.

Penduduk lokal Sabah telah banyak memeluk Islam yang sejak tahun 1930-an, yaitu: (1) Suku Kadazan. Suku Kadazan masuk dalam kategori sub-etnik suku Dayak (Wawancara: Iyen Yatim, 12-102017); (2) Suku Murut juga sangat banyak yang telah memeluk Islam. Suku Murut ini merupakan kategori rumpun sub-etnik suku Dayak yang aslinya terdapat di utara Kalimantan Timur, Brunei Sabah, dan Sarawak Malaysia Timur; dan (3) Suku Rungus juga rumpun suku yang telah melakukan konversi agama kepada Islam. Suku Rungus merupakan salah satu dari penduduk lokal di Sabah dan salah satu penduduk asli kepulauan Borneo (Kalimantan). 
Rungus biasa dikenal sebagai Dayak Dusun Rungus, momogun, Momogun Rungus, Momogun Laut, Dusun Laut atau Rungus.

Buletin USIA sebagai salah satu media penting secara rutin mempublikasikan berita-berita kegiatan dakwah baik di tingkat negeri (provinsi) maupun di tingkat daerah, baik secara personal maupun pemimpin organisasi. Semua kegiatan tersebut menunjukkan perkembangan yang pesat dalam sejarah perkembangan Islam di Sabah. Pemeluk Islam terus meningkat, di mana sejak 1930-an prosentase muslim sekitar $31 \%$ namun berdasarkan sensus penduduk 1973 ternyata meningkat tajam sebanyak 52\%. Dengan peningkatan tersebut pihak pemerintah telah menyetujui pendirian satu badan yang dinamakan Majlis Ugama Islam Sabah (MUIS) tanggal 26 April 1972 dan tidak lama berselang telah diakui pula Agama Islam menjadi agama rasmi di Negeri Sabah pada tanggal 23 September 1973 (Wawancara: Iyen Yatim, 12-10-2017). Organisasi USIA secara intens membangun kerjasama dengan berbagai organisasi di Negeri Sabah maupun lainnya antara lain dengan pihak Jabatan Hal Ehwal Agama Islam Sabah (JHEINS), Majlis Ugama Islam Sabah (MUIS), Yayasan Dakwah Islamiah Malaysia (YADIM), dan Angkatan Belia Islam Malaysia (ABIM). Tujuan membangun kerjasama adalah untuk memudahkan proses dakwah dan membina kaderisasi dakwah dalam organisasi USIA. Berselang beberapa hari setelah USIA didirikan, Tun Datu Haji Mustapha bin Datu Harun memanggil semua anggota Majlis Tertinggi USIA untuk mengadakan satu musyawarah khusus bertempat di Pejabat USIA di bangunan Sabah Institution di Kampung Air, kota Kinabalu. Musyawarah tersebut dimulai setelah Maghrib dan berakhir jam 04 pagi. Dalam musyawarah tersebut Tun Mustafa meminta anggota Majlis Tinggi USIA diberi kekayaan oleh Allah agar supaya memberikan sumbangan kepada organisasi dakwah USIA (Emin Madi, 2009: 40-41).

Tugas utama USIA (United Sabah Islamic Association) adalah melancarkan gerakan dakwah 
melalui ceramah-ceramah mengenai agama Islam yang mesti dijalankan oleh para pendakwah USIA. Mereka dibagi tugas oleh Tun Datu Haji Mustapha bin Datu Harun. Ceramah mengenai Cara dan Teknik Menjalankan Dakwah dipertanggungjawabkan kepada Tuan Haji Ag Sahari Abdul Latif. Adapun mengenai Dua Kalimah Syahadah dan Cara-cara Mengislamkan disampaikan oleh Tuan Haji Ahmad Pakir. Keduanya adalah pengurus Inti di unit dakwah USIA (United Sabah Islamic Association). Selain itu, kepada semua pendakwah USIA agar menggunakan pendekatan dengan menekankan pada "Islam Adalah Agama Perpaduan" dalam ceramah-ceramah mereka (Emin Madi, 2009: 41).

USIA terus proaktif giat menjalankan program-program dakwah Islamiah kepada masyarakat pedalaman di Sabah. Menurut Datuk Hj. Awang Sahari bin Abdul Latif (2001: 1-3), pada tahun 1970 USIA telah melancarkan gerakan dakwahnya ke seluruh Negeri Sabah. Sasaran dakwahnya terdiri dari kaum Kadasan Dusun dan Murut di daerah- daerah pendalaman yang tidak mempunyai anutan agama (Pagan). Upaya yang dilakukan USIA menunjukkan hasil yang membanggakan karena lebih dari 50,000 orang laki-laki dan perempuan dewasa telah memeluk agama Islam. Para muallaf mencapai 100,000 orang jika dijumlahkan bersama anak-anak mereka. Secara tidak langsung, jumlah umat Islam di Negeri Sabah pada saat itu meningkat kepada $52 \%$ dari seluruh jumlah penduduk Sabah yang menganut berbagai agama. Selain dari itu, jumlah anggota parlemen atau Ahli Dewan Undangan Negeri (ADUN) juga telah meningkat menjadi 2/3\% mayoritas di parlemen. Karena itulah ADUN atau Ahli Dewan Undangan Negeri ini juga merupakan pendakwah dan juga pemimpin-pemimpin dalam USIA. Akhirnya dengan rasio peningkatan jumlah anggota parlemen ADUN Negeri Sabah menjadi kepada 2/3\% perwakilan orang Islam, maka MAIS atau Majlis Agama Islam Sabah dapat didirikan dan telah disetujui oleh Dewan Undangan Negeri pada 26 April 1972 (Nur A'thiroh 
Masyaa'il Tan \& Abdul Imam Basirun 2014: 8).

Selain dari itu, ketua menteri Sabah Tun Mustafa setelah melihat banyaknya warga Sabah yang telah masuk agama Kristen oleh missionaris Inggris sewaktu berkuasa di Sabah sebanyak lebih kurang 60\%, maka perlu ada penambahan para muballigh yang dapat diandalkan dan diharapkan tenaganya untuk menyebarkan dan mengembangkan Islam di Sabah (Wawancara: Iyen Yatim, 12-10-2017). Maka untuk itu, pada tahun 1974 Tun Mustafa meminta kepada ulama Indonesia, yaitu Buya Muhammad Natsir agar sudi kiranya mencari kader-kader muballigh yang akan dikirim ke Sabah. Atas permintaan tersebut, maka Buya Muhammad Natsir meminta kepada Buya Hamka untuk mencarikan muballigh tersebut. Selanjutnya Buya Hamka meminta kepada Bahrum Jamil yang saat itu menjadi Rektor Universitas Jam'iatul Washliyah untuk mencari muballigh dimaksud. Maka Bahrum Jamil mencarikan muballigh tersebut di Medan dan sekitarnya dengan terlebih dahulu mereka diuji dan diseleksi komitmennya terhadap dakwah Islam (Wawancara: Iyen Yatim, 12-10-2017).

Banyak yang berkeinginan dan mendaftar kemudian diuji oleh Mufti Sabah. Saat itu mereka diuji di Universitas Islam Sumatera Utara dengan 12 mata pelajaran. Ternyata yang dapat lulus ujian hanya 18 orang. Maka mereka yang berjumlah 18 orang tersebut dikirim ke Sabah untuk menjadi muballigh. Dari 18 orang tersebut yang masih hidup sekarang hanya 6 orang lagi, selebihnya sudah meninggal dunia (Wawancara: Iyen Yatim, 12-102017). Muballigh lain yang didatangkan ke Sabah pada tahun 1976 adalah Suharto dan Masduki, mereka adalah tamatan Gontor pada tahun 1976, salah satu dari teman mereka yang tamat tersebut adalah orang Sabah yang sekolah di Gontor. Dia mengajak mereka ke Sabah, pada mulanya untuk membuka sekolah terpadu (agama dan umum), tetapi karena sesuatu dan lain hal, cita-cita tersebut tidak dapat terwujud, maka keduanya diterima sebagai muballigh di USIA (United Sabah Islamic Association) atau Pertumbuhan Islam 
Seluruh Sabah sampai sekarang tetap sebagai muballigh di tempat tersebut (Wawancara: Suharto, 11-10-2017).

Faktor yang membuat pejabat Sabah mendatangkan mubaligh dari Indonesia ke Sabah bukan dari Kelantan atau Terangganu karena menurut pengalaman mereka, muballigh dari Kelantan dan Terangganu tidak ada tolak angsur, seperti ada di antara orang yang masuk Islam, merasa keberatan karena harus melaksanakan shalat subuh atau keberatan kalau tidak boleh berjudi; muballigh Malaysia menegaskan bahwa bila tidak menjalankan kewajiban shalat atau telah masuk Islam tapi masih berjudi maka statusnya akan keluar dari Islam, sementara muballigh berasal dari Indonesia menegaskan bahwa, masuk Islam tidak sulit, boleh meninggalkan shalat tapi pada tahaptahap berikutnya harus menjalankan shalat, datanglah shalat Subuh ke masjid, tak payah, tapi nanti kapankapan kalau sudah tak sulit lagi tinggalkan main judi. Kata orang Sabah cara seperti inilah yang disenangi mereka dengan muballigh yang berasal dari Indonesia (Wawancara: Salim, 12-10-2017). Untuk mendukung cepatnya perkembangan Islam di Sabah maka pihak JHEAINS (Jabatan Hal Ehwal Agama Islam Negeri Sabah) membentuk Koordinator Ceramah di dalam Jabatan Dakwah yang bertugas mengirim muballigh ke daerah-daerah yang dijadikan tempat penyebaran Islam atau menerima permintaan dari daerah yang meminta muballihg dikirim ke daerah mereka (Wawancara: Awaluddin Nasution, 12-10-2017). Jabatan ini diduduki oleh Ibu Aisyah binti Okhdin, beliaulah yang mengatur penceramah ke daerahdaerah secara bergiliran atau bersama-sama. Adapun mereka yang menjadi muballigh di Jabatan Muballigh JHEAINS (Jabatan Hal Ehwal Agama Islam Negeri Sabah), antara lain, Suraiyah binti Salim; Awaluddin Nasution; Kalana Liyas; Romzi bin Rahman; Lilis Mulyani; dan Maria Hasibuan.

Jabatan Dakwah ini selain mengurus muballigh yang akan ceramah, juga bertugas mengurus orang yang akan berpindah agama ke 
agama Islam. Bagi mereka yang sudah lama masuk Islam tetapi belum memiliki surat pernyataan dan surat-surat lainnya maka mereka didaftar ulang tetapi bagi mereka yang baru akan masuk Islam mereka di daftar dan diislamkan. Pada tahun 2016 mereka yang masuk Islam mencapai 1900-an orang sedangkan pada tahun 2017 sampai bulan Oktober 2017 sudah mencapai 1300 Orang. Suku terbesar yang ada di Sabah adalah suku Kadazan Dusun, dulu mereka yang terbanyak masuk Kristen, tetapi sekarang merekalah yang terbanyak masuk Islam.

\section{Konflik Sabah dengan Kesultanan Sulu}

Pada saat jatuhnya Malaka di tangan Portugis pada tahun 1511 telah mendorong Sultan Brunei mengambil alih kepemimpinan Islam dari Malaka. Selama pemerintahannya Sultan Brunei memperluas pengaruhnya hingga ke Utara Sulu mencapai sebelah Selatan dan Barat Borneo. Kekuasaan Sultan Brunei yang mencakup wilayah yang cukup luas hingga tepi-tepi perbatasan
Kalimantan dan selatan Filipina. Pada masa pemerintahannya, Sultan Brunei mendapat permasalahan yang ditimbulkan dari dalam wilayahnya sendiri yaitu upaya pemberontakan oleh masyarakatnya. Pemberontakan yang cukup besar dan Sultan Brunei cukup kualahan sehingga beliau meminta pertolongan secara resmi kepada Sultan Sulu untuk ikut membantu menyelesaikan permasalahan ini. Tawaran tersebut tidak hanya sekedar tawaran membantu tetapi dengan tawaran jika pihak Sulu berhasil melawan para pemberontak tersebut maka hadiah yang sangat besar akan diberikan. Hadiah tersebut berupa otoritas wilayah yang mencakupi Sabah yang saat ini berada ditanah Malaysia. Seperti gayung bersambut akhirnya Sulu dapat meredamkan permasalahan pemberontakkan dan sesuai yang dijanjikan akhirnya Sultan Sulu mendapat otoritas wilayah yang pernah dijanjikan Sultan Brunei. Pasca penyerahan wilayah dari Sultan Brunei wilayah Sabah menjadi milik Sulu terdapat banyak perselisihan mengenai faktafakta yang ada pada masa sejarah 
terdahulu (Ade Agnieska Yonita, 2014: 509).

Pihak Sulu dan Malaysia memiliki persepsi yang berbeda. Sulu jelas-jelas menguatkan pendapatnya bahwa apapun yang terjadi Sabah adalah milik mereka dan tanah leluhur yang mereka kuasai terdahulu adalah tanah yang sudah menjadi wilayah kepemilikan hingga anak cucu mereka. Pasca adanya kolonialisasi Inggris dan Spanyol timbul berbagai perbedaan persepsi mengenai wilayah Sabah. Inggris memberi status Piagam Kerajaan untuk Sabah. Tapi belakangan Spanyol yang menjajah Sulu, dan Belanda yang menjajah sebagian Kalimantan memprotes. Pada 30 Maret 1963, Inggris mengklarifikasi dengan menyatakan "Kedaulatan tetap pada Sultan Sulu" dan perusahaan Dent itu hanya sebagai pengelola dengan membayar uang sewa (Ade Agnieska Yonita, 2014: 509).

Sewa yang dibayarkan dari pihak Inggris tersebut hingga saat ini terus berlangsung, sejak Sabah dikelola Inggris yang digunakan sebagai akses wilayah perdagangan hingga kemerdekaan Malaysia terbentuk. Hingga sampai tahun 2005 pembayaran masih tetap dilakukan oleh Malaysia kepada pewaris Kesultanan Sulu. Namun, pasca tahun 2005 pembayaran akan sewa tersebut terjadi pemberhentian secara sepihak. Adanya pemberhentian tersebut karena pihak Malaysia menganggap sudah selesai dalam hal pembayaran dan dinilai cukup sebagai beli tanah. Adanya persepsi tersebut membuat pihak Kesultanan tidak terima karena menganggap bahwa uang yang selama ini diterima dan dibayarkan adalah hanya sebagai uang sewa bukan sebagai uang untuk pembayaran beli Sabah.

Dalam catatan sejarah tentang Sabah, sejak tahun 1473-1658 M, Sabah dahulunya dikenal sebagai North Borneo merupakan wilayah Kesultanan Brunei. Namun, pada tahun 1658 M., Sultan Brunei memberikan wilayah ini kepada Sultan Sulu. Pemberian ini ada hubungannnya dengan balas jasa kepada Sultan Sulu yang telah mampu membantu meredam perang sipil di Kesultanan Brunei. Selanjutnya Pada tahun 1761 M, 
Alexander Dalrymple seorang pejabat koloni Inggris (Bristish East India Company), melakukan perjanjian dengan Sultan Sulu untuk menyewa Sabah sebagai pos perdagangan koloni Inggris. Kesepakatan sewa-menyewa itu termasuk penyediaan tentara pengamanan dilakukan oleh Kesultanan Sulu dalam mengusir koloni lain, yakni Spanyol yang juga berambisi untuk menguasai wilayah tersebut. Di samping itu, pada tahun 1846 M, Pantai Barat Borneo diserahkan oleh Sultan Brunei ke Inggris. Jadilah pantai barat Borneo yaitu Sarawak juga menjadi bagian dari koloni Inggris.

Black menjelaskan bahwa pada tahun 1878 M Sabah telah dibagi pada dua bagian yaitu Pantai Barat Sabah dittapkan sebagai daerah kekuasaan Kesultanan Brunei. Sedangkan bagian Timur Sabah telah ditetapkan sebagai bagian dari kekuasaan Kesultanan Sulu Menurut Saat dan Jumilah Bagian Timur Sabah diambil oleh Kesultanan Sulu dan Suku Tausog setelah berakhirnya perang saudara pada masa pemerintahan Sultan Muhyiddin yang memerintah 1673-1690 (Saat H. Awang Damit \& Jumilah Jakfar, 2003: 675). Kemudian pada tahun 1881 "Syarikat Berpiagam Borneo Utara" mengambil alih Sabah setelah mendapat persetujuan Kerajaan Inggris dengan berlandaskan perjanjian sewa antara Sultan Abdul Momin dan Konsul Agung Amerika Charles Lee Moses tahun 1865. Sabah telah dijadikan kawasan perdagangan untuk mendapat keuntungan yang lebih besar dari pemilik lama secara bergantian berpindah dari Charless Lee Moses kepada Joseph Wilfred Torry, kemudian pindah lagi ke Gustavus Baron Von Overbeck selanjutnya baru "Syarikat Berpiagam Borneo Utara" atau lebih dikenal dengan British North Borneo Chartered Company (BNBCC) (Wright L.R: 1970, 142). Selanjutnya dilantiklah Gubernur Borneo Utara pertama William Hood Treacher (1881-1887 M).

Hak sewa jatuh ke penguasa koloni Inggris Alfred Dent yang kemudian membentuk perusahaan yang dikenal dengan British North Borneo Company. Pada tahun 1885 
M, ada kesepakatan baru antara Inggris, Spanyol, dan Jerman, dengan menandatangani Protokol Madrid yang isi perjanjian tersebut substansinya mengakui kedaulatan Spanyol di Kepulauan Sulu. Pengakuan ini sebagai ganti dari pelepasan Spanyol atas segala klaimnya di North Borneo atau Sabah untuk mendukung Ingris. Beberapa tahun kemudian masih di akhir abad ke 19 M tepatnya tahun 1888, Sabah resmi menjadi wilayah protektorat koloni Inggris yang kemudian menduduki negeri-negeri persekutuan Malaya (Malaysia) sebagai wilayah jajahan. Setelah Perang Dunia II, Inggris berniat mengembalikan Sabah ke Kesultanan Sulu. Untuk kelancarannya langkahlangkah dilakukan melalui pemungutan suara. Tujuan diadakan pemungutan suara adalah penentuan rakyat Sabah memilih bergabung dengan Federasi Malaysia atau kembali ke Kesultanan Sulu. Dari hasil pemungutan suara didapatkan bahwa, rakyat Sabah lebih memilih bergabung ke Malaysia daripada kembali ke Kesultanan Sulu.
Keputusan rakyat Sabah ini merupakan final.

Namun, memasuki dekade kedua abad 21 M, Kesultanan Sulu memberanikan diri untuk mengklaim Sabah sebagai bagian dari kekuasaanya. Hal ini tentu saja dipengaruhi oleh bertambahnya kekuatan Kesultanan Sulu dari Pejuang Moro. Pejuang Moro ikut membantu Kesultanan Sulu untuk mendapatkan Sabah yang dianggap sebagai wilayahnya karena Sulu merupakan daerah basis kedua dari kekuatan MILF. Dilihat catatan sejarah sejarah, Sabah merupakan milik Kesultanan Sulu dulunya. Sikap dan perilaku konflik antara Malaysia dengan tentara Kesultanan Sulu adalah keras dan bertahan. Pihak Malaysia menyatakan bahwa mereka tidak akan melepaskan Sabah ke tangan Kesultanan Sulu, bahkan Malaysia akan menambah jumlah pasukan untuk mempertahankan Sabah. Sedangkan pihak kesultanan Sulu juga bertekad akan terus melancarkan serangan hingga Sabah berhasil diduduki. Sultan Sulu Jamalul Kiram III menegaskan 
tentara Kesultanan Sulu tak akan menyerah dan tetap bertahan.

Pada tahun 2013 M. konflik kepemilikan Sabah muncul kembali, di mana Kesultanan Sulu memberanikan diri mengklaim Sabah dengan mengirim tentaranya ke Sabah. Hal ini tentu saja dipengaruhi oleh bertambahnya kekuatan Kesultanan Sulu dari Pejuang Moro MILF (Moro Islamic Libration Front) berdiri 1984 M. Selanjutnya pada tahun 1990 M MNLF (Moro National Libratin Front) menerima kesepakatan daerah otonomi Muslim Mindanao "Nagsasariling Rehiyon ng Muslim sa Mindanaw" (NRMM; Daerah Otonomi Muslim Mindanao)“, tetapi MILF Menolak. Pada tahun 2013 perwakilan MILF \& Filipina berhasil merumuskan perjanjian damai yang diharapkan bisa mengakhiri aktivitas pemberontakan MILF secara permanen. Karena wilayah Filipina Selatan akan memperoleh otonomi lebih luas, kebebasan menggunakan hukum Islam, dan jatah keuntungan hasil eksploitasi Sumber Daya Alam yang lebih besar bagi komunitas setempat (Abd. Ghofur, 2016: 184).
Kesultanan Sulu merupakan langkah penting dalam tradisi sejarah politik suku Tausog. Kekuasaan Sultan Sulu dimulai sejak tahun 1450 M yang dipimpin oleh Sultan Syarif Abu Bakar, sampai akhirnya kekuasaan ini berakhir pada tahun 1915 seiring kuatnya tekanan politik kekuasaan kolonial Amerika. Hal ini berarti kekuasaan Kesultanan Sulu bisa bertahan hingga 500 tahun. Namun, sebagian ahli sejarah percaya bahwa kesultanan sebagai suatu sistem baru mengalami kejatuhan sejak tahun $1936 \mathrm{M}$, ketika persemakmuran menolak untuk mengakui setiap pewaris yang menentang kekuasaan Sultan Jamalul II terakhir berkuasa (Abd. Ghofur, 2016: 184). Formasi komunitas politik yang terorganisir sebagai hasil dari unifikasi banua (komunitas) yang terpusat memberikan sumbangan berharga bagi Suku Tausog di kesultanan Sulu. Kesultanan Sulu bukan hanya melingkupi masyarakat suku Tausog, tetapi juga mengendalikan beberapa suku lainnya seperti suku Samal, Yakanes, Badjau yang muslim, termasuk suku-suku yang terletak di 
wilayah Zamboanga dan Basilan (Charmen A abu Bakar, 1993: 199). Kesultanan Sulu juga berperan dalam melegitimasi kekuasaan wilayah Daar al-Islam, yaitu wilayah yang berupaya untuk menerapkan syariat Islam dan hukum Islam.

Sikap yang keras dan bertahan hingga situasi jelas siapa yang menang dan kalah, menunjukkan konflik Malaysia dan Sulu ini semakin bereskalasi. Dilihat dari aktor dalam konflik Malaysia dan Sulu ini, bukan hanya pihak Kesultanan Sulu yang bertentangan dengan polisi Malaysia. Di pihak Sulu ada Pejuang Moro yaitu MILF (Moro Islamic Libraion Front) yang akan membantu untuk mendapatkan wilayah Sabah, sedangkan di pihak Malaysia dibantu oleh pemerintahan Filipina. Presiden Filipina Beniqno Aquino, melalui konferensi pers menyampaikan kepeduliannya atas keamanan Filipina. Beniqno juga meminta pasukan Kesultanan Sulu pulang ke Filipina dan menyelesaikan masalah dengan cara perundingan. Sedangkan Kesultanan Sulu pada dasarnya tidak menentang kekuasaan pemerintahan sah Filipina, sehingga Presiden Beniqno Aquino tidak akan mengambil tindakan terhadap Kesultanan Sulu.

\section{Kesimpulan}

Berdasarkan uraian di atas, maka dapat diambil beberapa kesimpulan berikut ini.

Pertama, Islam masuk ke Sabah secara intensif terjadi pada abad ke $16 \mathrm{M}$, dimulai dari kawasan pantai Barat Sabah, yaitu berasal dari Kesultanan Brunei. Persebaran Islam dari Brunei ke Sabah terjadi pada masa Sultan Bolkiah (berkuasa 14851524 M) karena beliau termasuk pemimpin yang sangat suka berpetualangan ke berbagai wilayah disamping mendakwahkan Islam juga memperluas daerah taklukan (daerah kekuasaan). Persebaran penduduk melayu Brunei secara bertahap bermigrasi ke kawasan pantai Barat Sabah, sekaligus persebaran Islam pun terjadi. Puncak kejayaan Islam di Kesultanan Brunei adalah pada masa Sultan Bolkiah berkuasa karena perluasan pengaruhnya bukan saja di wilayah Borneo (Brunei), tetapi juga meliputi 
gugusan kepulauan Sulu di Filipina Selatan dan Pantai Barat Sabah.

Kedua, Persebaran Islam dari Kesultanan Sulu kepada penduduk lokal Sabah sekitar abad ke-17 M sebagai akibat dari tekanan dan serangan koloni Spanyol (1521-1898 M) di Philipina Utara (Luzon, Visayas) hingga Selatan (Mindanao, Sulu, Basilan, Tawi-tawi Cota-Bato). Sebagian muslim Mindanao dan Sulu melakukan migrasi ke pantai Timur Sabah untuk mendapatkan kehidupan yang lebh baik dan aman.

Perkembangan Islam di Sabah setelah Malaysia merdeka dominan dipengaruhi oleh USIA (United Sabah Islamic Association). Organisasi USIA lahir karena penggabungan dari tiga organisasi terkemuka di Sabah, yaitu: (1) Persatuan Islam Putatan (PIP) yang didirikan oleh Haji Ag Sahari Abd. Latif, (2) Persatuan Islam Tawau (PIT) yang dipelopori oleh Orang Kaya-Kaya (OKK) Zainal Kerahu, dan (3) Persatuan Islam Sabah (PIS) yang dimotori Datuk Haji. Mohd Kassim Bin Haji Hasyim. Langkahlangkah ini mereka lakukan agar efektifitas dan jangkauan dakwah lebih fokus. Awalnya tiga organisasi ini bergerak secara terpisah karena tidak memiliki kekuatan dalam dakwah Islam. Selanjutnya muncul ide menyatukan ketiga gerakan Islam ini menjadi sebuah organisasi yang lebih kuat.

Perubahan besar terjadi di Sabah dalam sejarah perkembangan Islam dan dalam ranah sejarah politik di negeri ini. Hal ini tidak bisa dilepaskan dari peran USIA di bawah kempimpinan Tun Datu $\mathrm{Hj}$. Mustapha sebagai ketua Menteri Sabah sekaligus sebagai Ketua USIA. Gerakan dakwah berjalan lancar dan USIA berhasil mengislamkan puluhan ribu penduduk negeri ini terutamanya masyarakat suku kaum Kadazan/ Dusun, Murut, Rungus sejak tahun 1970-an. Hakikat dari kegiatan dakwah USIA tersebut menjadi faktor dominan dalam sejarah perkembangan Islam di Sabah. Organisasi USIA membangun kerjasama dengan organisasi Islam untuk memudahkan proses dakwah dan membina kaderisasi dakwah. Secara intens USIA membangun kerjasama dengan berbagai 
organisasi di Negeri Sabah maupun lainnya antara lain dengan pihak Jabatan Hal Ehwal Agama Islam Sabah (JHEINS), Majlis Ugama Islam Sabah (MUIS), Yayasan Dakwah Islamiah Malaysia (YADIM), dan Angkatan Belia Islam Malaysia (ABIM).

\section{Daftar Kepustakaan}

A. Hasymy. (1994). Sejarah Masuk dann Berkembangnya Islam di Indonesia. Bandung: AlMa'arif.

Abdul Aziz Thaba. (1998). Islam dan Negara Dalam Politik Orde Baru. Jakarta: Gema Insani Press.

Abdul Ghofur. "Dinamika Muslim Moro Di Filipina Selatan Dan Gerakan Sparatis Abu Sayyaf”. Jurnal Sosial Budaya 13, no. 1 (2016)

Ahmad Mansur Surya Negara. (2010). Api Sejarah. Bandung: Salamadani.

Azyumardi Azra. (1994). Jaringan Ulama Timur Tengah dan Kepulauan Nusantara Abad XVIIdan XVIII M. Bandung: Mizan.

-------. Perspektif Islam di Asia Tenggara. Jakarta: Yayasan Obor.

Badri Yatim. (1997). Historiografi Islam. Jakarta: Logos.
Black. I. (1976). "Inter-Etnic and Culture Change Under Colonial Rule: A Study of Sabah". dalam Appel (Ed.). Studies In Borneo Societes: Social Process and Antropological Explanation. Michigan: East Asian Studies.

Dardiri, Dkk. (2006). Sejarah Islam Asia Tenggara. Riau: ISAIS UIN Suska Riau.

Datuk Gamdin Buyong. (1995). Islam di Sabah Peranan Putatan Dalam Perkembangannya. Sabah: Majlis Ugama Islam Sabah Kota Kinabalu.

Deliar Noer. (1986). Bunga Rampai dari Negeri Kanngguru Australia. Jakarta: Panji Masyarakat.

Dokumen Gazetir. Negeri Sabah. Jawatan Kuasa Kebangsaan Nama Negeri (JKNG) Malaysia. Desember 2012.

Dudung Abdurrahman. (1999). Metode Penelitian Sejarah. Jakarta: Wacana Ilmu.

Emin Madi. (2009). SinarPerjuangan USIA. Kota Kinabalu: NS Printing Service.

Funston, John. (Ed.). (2001). Government and Politicsin Southest Asia. Singapure: ISEAS.

Kementerian Kebudayaan, Beliau dan Sukan Brunei Darussalam. (2011). Prosiding, Seninar Sejarah Borneo Ke-2.

Marwati Djuneid \& Nugroho Noto Susanto. (1988). Sejarah 
Nasional Indonesia II. Jakarta: Balai Pustaka.

Mataim Bakar. (2006). Fonologi Dialek Melayu Brunei: Satu Analisis Teori Standart Fonologi Generatif.

Najion Jamil. (2010). Pembentukan Malaysia dan Impaknya Terhadap Perkembangan Islam di Sabah. Sabah: Jabatan Hal Ehwal Agama Islam Negeri Sabah.

Nur A'thiroh Masyaa'il Tan Binti Abdullah \& Abdul Imam Basirun (2014). "Pendekatan Dakwah United Sabah Islamic Association (USIA) Terhadap Pribumi Di Negeri Sabah: Tinjauan Dari Ekonomi". Seminar Antara Bangsa Dakwah \& Etnik.

Pangeran Fatimah Binti Datuk Sidek. "Sejarah Karangbunai Berasal Dari Peristiwa Kapal orang Brunei Karam di Ketuai Oleh Pangeran Abdullah". Prosiding. Senarai Sejarah Borneo Ke-2.

Pehin Jawatan Dalam, Seri Maharaja Dato Dr. Haji Awang Mohd. Jamil Al-Sufri. (1997). Tarsilah Brunei II: Zaman Kegemilangan dan Kemasyhuran. Pusat Sejarah Brunei: Bandar Sri Begawan.

Pg. Mohammad bin Pg Abdurrahman. (2003). Brunei Darussalam Pusat Penyebaran Islam di Abad ke 16M; Satu Sumbangan dari Malaka. Institut Pengajian Islam: Bandar Sri Begawan.

Rosli bin Ampal (2013). Jejak Kesultan Brunei di Sabah. Jilid
1 dan 2. Pusat Sejarah Brunei Kementerian Kebudayaan, Belia dan Sukan: Negara Brunei Darussalam.

Sauddin Zuhri. (1984). Sejaraah Kebangkitan Islam dan Perkembangannya di Indonesia. Bandung: al-Maarif.

Selamet Muljana. (1968). Runtuhnya Kerajaan Hindu Jawa dann Timbulnya Negara-negara Islam di Nusantara. Jakarta: Bhatara.

Syamruddin Nasution. (2013). Sejarah Peradaban Islam. Riau: Yayasan Pusaka Riau.

Tim Penulis. (2001). Ensiklopedi Islam. Jilid 1. Jakarta: PT Ichtiar Baru Van Hoeve.

Taufik Abdullah. (1994). Sejarah dan Masyarakat: Lintasan Historis Islam di Indonesia. Jakarta: Yayasan Obor Indonesia. 